\title{
Navigating the First Year: Transition and Adjustment Experiences of International Students of Color at a Predominantly White Institution
}

\author{
Christina W. Yao, Ph.D., University of South Carolina
}

Jennifer N. Rutt, M.A., University of Nebraska - Lincoln

Kaleb Briscoe, MBA, M.S. Graduate, University of Nebraska - Lincoln Alexandra Kirshenbaum, M.Ed, The University of Chicago Matthew W. Knight, Purdue University Kathleen J. Buell, M.A., Eastern Washington University

This study was funded by the ACUHO-I Funded Research Grants Program and the NODA Catalyst Grant.

International student mobility has been a highly discussed topic in higher education in the United States (U.S.). Yet current geo-political issues necessitate a re-examination of how international students, especially those who would be considered students of Color, are transitioning to U.S. higher education institutions. Findings from three interviews that spanned participants' first year on campus include the importance of social interactions, challenges with academic adjustments, and navigating the effects of politics. Suggestions for student affairs practice are addressed, including pre-sojourn connections and peer engagement.

International student mobility has been a highly discussed topic in higher education in the United States (U.S.). As a result, multiple studies have been conducted related to international student adjustment (e.g., Andrade, 2006; Smith \& Khawaja, 2011), sense of belonging (e.g., Glass \& Westmont, 2014; Yao, 2015, 2016a, 2016b), and peer interactions (e.g., Abe, Talbot, \& Gellhoed, 1998; Trice, 2004). More recently, scholars are increasingly 
addressing challenges international students face related to discrimination, neo-racism, and othering (e.g., Fries-Britt, George Mwangi, \& Peralta, 2014; Lee \& Rice, 2007; Yao, 2018). The recent emphasis on negative experiences by international students highlight the unique needs of this population, particularly within contemporary U.S. contexts.

Although international student mobility to the U.S. is a heavily discussed topic, current geo-political issues necessitate a re-examination of how international students are transitioning to U.S. higher education institutions. A recent decline in new international student enrollment numbers in the U.S. has raised questions on how to best support students in today's climate. In the 2017/18 academic year, new international student enrollment dropped over six percent from the previous year (Institution for International Education [IIE], 2018). Some reasons cited for the decline in international student enrollment included difficulties with visa applications, socio-political contexts of the U.S., and decisions to attend higher education institutions in other countries (IIE, 2018). In addition, the majority of international students in the U.S. tend to originate from what would be considered non-predominantly White and non-predominantly English-speaking countries. Thus, in the U.S. context, many of these international students are considered racial and/ or ethnic minorities and may be considered students of Color (Yao, George Mwangi, \& Malaney Brown, 2019). Because the experiences of international students of Color may be unique, it necessitates a closer examination on how these students transition and adjust to U.S. colleges and universities, particularly within the current geo-political climate. The purpose of this study is to understand transition and first-year experiences of international students of Color at a predominately white institution (PWI). We seek to answer, what are international students of Color's perceptions of their transition and adjustment to a PWI during their first year of college?

\section{International Student Transition to the United States}

International students arriving to the U.S. must navigate both a new collegiate community as well as U.S. culture and norms. In a review of literature spanning from 2009-2018, Brunsting, Zachry, and Takeuchi (2018) examined studies related to undergraduate international student adjustment within the U.S. educational context. They found an increased emphasis on international 
students' psychosocial adjustments to the U.S., with many articles emphasizing acculturative stress, anxiety, and depression. More broadly, challenges related to international student transition tend to center around issues related to English language proficiency, psychosocial adjustment, and social interactions (Andrade, 2006; Smith \& Khawaja, 2011). For example, English language proficiency was found to be a factor in Chinese international students' overall sense of belonging, particularly in relation to the students' social interactions with domestic students in the residence halls (Yao, 2016a, 2016b). Perceived English language barriers for non-native English speakers may be a source of frustration for international students, especially those from China, in their sociocultural adjustment (Briguglio \& Smith, 2012; Edwards, Ran, \& Li, 2007; Li, Chen, \& Duanmu, 2010; Yao, 2016a, 2016b).

Black international students may also experience unique challenges when transitioning to a new U.S. institution, as this student population must navigate being "Black within Black" (George Mwangi \& Fries-Britt, 2015). For example, George Mwangi (2016) conducted a study on Black international students' sense of belonging to a Historically Black College and University (HBCU). Students reported overall feelings of positivity towards their campus environment; however, participants would often relate more with their nationality, and despite racially belonging, they "still appeared to see themselves on the periphery of mainstream campus culture" (George Mwangi, 2016, p. 1028). As a result, Black international students would seek friends who were also foreign-born as a way to mitigate the feelings of disconnection from the campus community.

Hayes and Lin (1994) argued that individual differences must be considered when attempting to understand why some students are more likely than others to encounter barriers to potential support. In addition, social support networks are key to students' success in transition and limit barriers to obtaining support. Practices that assist international student transition include a course related to academic and cultural transitions to the U.S. educational context that increased students' intercultural competency as well as feelings of campus belonging and social support (Brunsting, Smith, \& Zachry, 2018). As another curricular example of international student support, Yan and Sendall (2016) found that a tailored First-Year Experience (FYE) program for international students better prepared international students for college life 
and contributed to their social and emotional development.

In addition, involvement in campus organizations contributed to international students' social capital on campus, which included increased interactions with domestic students and increased sense of belonging (Glass \& Gesing, 2018). Specifically, involvement with campus organizations that were related to international students' cultural heritages led to stronger connections with friends from other cultures, which led to a greater sense of belonging to the university. Overall, participation in friendships and networks at the university contributed to increased frequency and comfort with engaging socially with others from different cultures (Glass \& Gesing, 2018; Soria \& Troisi, 2014). The interactive component with domestic students, particularly in residence halls, could lead to implications for international students' overall sense of belonging (Yao, 2016a).

\section{Conceptual Framework}

The theoretical framework used to guide this study is Schartner and Young's (2016) integrated conceptual model of international student adjustment and adaptation. This model incorporates a micro-level analysis, which aims to provide 1) a framework for synthesizing the increase in international student adjustment and adaptation research, 2) a template for replication in future studies, and 3) a method of heuristically understanding the process for practitioners and students both at home and internationally. Ultimately, this model addresses the gap in knowledge regarding psychological and sociocultural adjustment, and its impact on academic success.

Focusing on the experiences of international students, this conceptual model explores both intrapersonal and interpersonal development, making a distinction between pre-sojourn and in-sojourn factors. Pre-sojourn factors include items such as cultural empathy and open-mindedness, emotional stability, motivation for studying abroad, social initiative, flexibility, host language ability, and knowledge about the host country. During pre-sojourn there is a greater need for international students' language training and orientation through role playing to build intercultural competence and confidence (Fowler \& Blohm, 2004; Takahashi, 2009). In-sojourn factors include social support, as well as social contact with both host nationals and other international students. When compared with domestic students, 
international students need additional efforts to achieve social connections to their new environments during the in-sojourn stage (Rienties, Beausaert, Grohnert, Niemantsverdriet, \& Kommers, 2012). Those international students who have strong support systems typically have lower levels of stress and higher levels of sense of belonging (Russell, Rosenthal, \& Thomson, 2010).

Additionally, the model analyzes adjustment and adaptation across three areas: academic, psychological, and sociocultural. Academic adjustment is the process in which international students engage to overcome the demands of academic rigor such as adapting to the teaching and learning styles of the host university (Ryan, 2005). Psychological adjustment focuses on international students' affective responses, including the students' well-being and satisfaction to the new environment (Sam, 2001). Finally, sociocultural adjustment examines international students' cognitive and behavioral ability to perform at the host university, meaning how students fit in and interact with others on campus (Ward, Bochner, \& Furnham, 2005). Ultimately, these three areas are an intertwined process (Jindal-Snape \& Ingram, 2013), and call for the exploration of international students' responses through methodical approaches that examine adjustment and adaptation experiences over time (i.e., longitudinal studies).

\section{Methods and Methodology}

We conducted a qualitative study as a way to understand the lived experiences of first-year international students of Color at a large public landgrant research institution (pseudonym: Great Plains University [GPU]). We implemented a multiple case study design at GPU with each participant being defined as a case. Using Yin's (2018) replication design for our methodological procedures enabled us to use the exact same set of semi-structured interview questions for each participant. Stake (1995) explained that in a multiple case study it is important each participant is asked the same questions to validate the study's results; however, the semi-structured nature of the interviews also allowed for further questions or clarifications of participants' narratives. Denzin and Lincoln (2013) stated, "qualitative researchers study things in their natural settings, attempting to make sense of, or interpret, phenomena in terms of the meanings people bring to them" (p. 3). The research team interviewed the participants in a one-on-one setting in private locations 
on GPU's campus, which allowed the research team to understand the participant's environment.

\section{Data Collection}

We used purposeful sampling in an attempt to "discover, understand, and gain insight" by selecting "a sample from which the most can be learned" (Merriam \& Tisdell, 2016, p. 96). A solicitation email was sent to all international students at GPU asking for their participation in the study. Potential participants were identified by GPU's Registrar Office as meeting the criteria of being first-year, residential international students.

In order to reach saturation of data, we conducted three rounds of individual interviews during participants' first three semesters on campus. The first round of interviews was conducted between late September and midOctober 2017. A total of 19 undergraduate first-year international students between the ages of 18 to 25 elected to participate in the study with each participant selecting a pseudonym (Table 1). The second round of interviews were conducted between mid-February and early March 2018, with 15 returning participants. The third round of interviews took place in September 2018 and included 12 returning participants. Each participant received a \$10 gift card to Amazon.com at the completion of an interview. 
Table 1. Participant Demographics

\begin{tabular}{llll}
\hline Pseudonym & Age & Gender & Region of Origin \\
\hline Abi & 19 & Male & South Asia \\
Betina & 19 & Female & South America \\
Baby & 22 & Male & Central Africa \\
Esther & 18 & Female & Central Africa \\
Hun & 19 & Male & East Asia \\
Jan Are & 21 & Male & Central Africa \\
John Doe & 20 & Male & Central Africa \\
Johny & 20 & Male & Central Africa \\
Lenny & 21 & Male & Central Africa \\
Maria Alejandra & 18 & Female & South America \\
Muskan & 18 & Female & South Asia \\
Natalia & 18 & Female & East Asia \\
Nike & 25 & Male & Central Africa \\
NM & 18 & Male & South Asia \\
P & 21 & Male & Central Africa \\
Pinky & 18 & Female & South Asia \\
Ricky & 18 & Male & Central Africa \\
Sam & 17 & Male & North America \\
XL & 22 & Male & Central Africa \\
& & & \\
\hline
\end{tabular}

The primary data collection process included conducting 60-minute semi-structured interviews, which allowed for flexibility in the questions, but also sought specific information from the interviewees (Merriam \& Tisdell, 2016). Interviewing participants allowed the researchers to understand "the lived experience of other people and the meaning they make of that experience" (Seidman, 2006, p. 9). The researchers were able to develop a sustained relationship with each participant, making each interview unique. Stake (1995) explained that "qualitative researchers take pride in discovering and portraying the multiple views of the case. The interview is the main road to multiple realities" (p. 64). 
This study is part of a larger study with three rounds of interviews, with the first two interviews focused on understanding an international student's transition to GPU. Our interview questions began with what and why, because it helped "explore a central phenomenon" (Creswell \& Poth, 2018, p. 137). The first set of interviews included questions that focused on transitioning to the institution. The second round of interviews included questions that encouraged participants to reflect back on their first semester of college or lived experiences. The final set of interviews focused on participants reflecting on their first year of college. We followed Seidman's (2006) three-interview approach as a way to gain understanding of participants' experiences of the phenomenon, details of lived experiences, and experience reflection.

\section{Data Analysis}

Our data analysis process involved coding and identifying patterns. The first round of coding included a start list as described by Miles, Huberman, and Saldaña (2014) with multiple categories based on the interview questions. These categories reoccurred throughout a majority of the participant's transcripts. We utilized descriptive coding because "a descriptive code assigns labels to data to summarize in a word or short phrase - most often a noun the basic topic of a passage of qualitative data. These eventually provide an inventory of topics for indexing and categorizing" (Miles et al., 2014, p. 74). In our second cycle of coding, we clustered to condense, consolidate, and synthesize the data to create pattern codes (Miles et al., 2014; Saldaña, 2016). Clustering was selected as the approach for the second cycle coding, as it is a process of reformatting and re-sorting data to define similarities in the codes.

\section{Trustworthiness and Validity}

Trustworthiness was ensured through intercoder reliability for the first few interview transcripts. Intercoding allowed the research team to make sure each member of the team was properly coding the transcripts correctly and consistently, identifying the same themes. This allowed the researchers to validate and strengthen our coding process. Additionally, the research team met regularly and processed interviews both during and at the conclusion of each interview round, which allowed for peer debriefing. 
Finally, the researchers recognized the importance of reflecting on each individual's positionality in relation to the study and the participants. Understanding how their research lenses affect their approach to the research project assisted in the trustworthiness and validity of the current study. The lead researcher identifies as a Chinese-American woman, and her perspectives on internationalization are heavily influenced by her immigrant parents. She employs a critical perspective in examining student experiences. The second author identifies as a white American woman from the Midwest and currently works at a R1 Institution of Higher Education in an applied research role examining various facets of health in urban, rural, tribal, minority, and refugee populations. Her research focuses on identity, international education, social justice, and minority health disparities. The third author identifies as an African American woman and researcher who previously served as a student affairs practitioner. Her research focuses on underrepresented populations in higher education and campus racial climate incidents at PWIs. The fourth author identifies as a white American woman and was raised in the Midwest Region of the United States. She is a higher education professional who works with international populations at U.S. institutions and thus, understands the unique transition experiences of the research participants. The fifth author identifies as a white American man. His research focuses on the persistence of first-year students from rural communities at public land-grant research institutions. Finally, the sixth author identifies as a white American woman and was raised in the Rocky Mountain region of the United States. She is a student affairs professional working in housing and residence life, and the only member of the research team currently working in residence life. As such, she has a practical understanding towards the residential experiences of the research participants.

\section{Findings and Discussion}

Schartner and Young's (2016) model "makes a clear conceptual distinction between 'adjustment' and 'adaptation,' with the former reflecting a process (i.e., the experience of change), and the latter reflecting outcomes of this process" (p. 374). Our findings demonstrate the need to understand and dissect the experience of change, specifically the adjustment process, for international students of Color. Our findings are organized chronologically 
based on the first year of college, focusing specifically on pre-arrival expectations, first month experiences on campus, and reflection on the transition experiences in their first year.

\section{“Before Coming...": Expectations from Movies and Current Political Events}

Many of the study participants shared pre-sojourn factors that contributed to their transition to living and studying in the United States. Pitts (2009) stated that "[e]xpectation gaps are one contributor to adjustment stress" (p. 450). In order to understand adjustment stresses from pre-arrival to arrival, participants were queried about their initial expectations of studying at a U.S. institution of higher education.

Multiple participants held the perception that studying in the U.S. would be similar to how college is depicted in television and movies, including big cities, skyscrapers, more people, and parties. Johny recalled the expectation of seeing something like in the movies: "They show the college life here in the U.S. is full of parties...[and] people who don't care about study[ing]." Similarly, Abi discussed his expectations that everything "would be like big cities and everything like the certain movies. When I first came...I feel like there were less people and it was a quiet city. That was a bit different because I thought it was more like [movies]."

Some participants discussed their expectations of meeting people from different cultures and being exposed to diversity. John Doe specifically stated how he purposely looked for and wanted diversity exposure, stating: "that's something that I had to look at when I was, you know, choosing colleges. I had to look at the diversity there so that's kind of expected it to be like that. And that's pretty much what I wanted - diversity." Nike discussed the expectation of meeting and learning from "new people from different countries and different cultures because [the institution] is an international school. It has many, many students from different countries."

Due to the timing of the study - soon after Donald Trump was elected President, took office, and strict immigration bans were signed - participants were asked about their perspectives and expectations of the U.S. political climate prior to their arrival. Some participants admitted concerns about the political climate, specifically regarding immigration and racism. Lenny 
described that "before coming, we have been listening to radio saying U.S. is no longer accepting immigrants. It's claiming that people who are not native should go back to their country so we are a little bit worried about that." Benita was concerned that the anti-immigrant stance of the U.S. would prevent her from attending school. "After I applied, after I got accepted, my fears started like 'oh god, no no! I'm not gonna be able to go." Abi discussed concerns with immigration, but described working with embassy and immigration offices to ensure everything was done properly and legally so as not to be barred from entering or be deported once within borders. "I was thinking as long as I stay...within the law, I hope and think I will not be any problem. Like they will not deport me as long as I'm within the immigration rule."

XL considered the political climate early on in his school selection and acceptance. When news of "people not getting their president" became concerning, he reached out to a "friend who is here, [and] I asked him 'How the climate there?' He told me 'It's fine, there's no problem with those political stability." XL was not the only study participant concerned with political stability, as Ricky mentioned stability as a consideration prior to arrival. "At some point, yes, you had to think of a place that is being maybe assumed to be not political stability." Furthermore, racial incidents were also concerning to participants. John Doe described how his parents were scared for his safety stating, "'Do you have to go there? You're gonna, if you go there, there's going to be a bullet in your head."' The concerns from participants reflect some of the highlighted reasons which contributed to lower new international student enrollment to the U.S. (IIE, 2018). Also, participants who were vocal about concerns related to racial incidents and political stability reflected the concerns raised in previous studies in which international students, especially those considered students of Color, experienced discrimination and neoracism (Fries-Britt et al., 2014; Lee \& Rice, 2007; Yao, 2018).

Despite the early expectations, perspectives, and concerns, some participants discussed trying not to have expectations. John Doe described that expectations are misleading, as he "feel[s] that every country is very different and what you see on TV is always very different from what is actually happening." Furthermore, Benita talked about preparing herself through researching the school and activities in order to ready herself and not have misleading expectations. 
I didn't have any great expectations because I [was] really like "okay, I'm not gonna expect a lot because I don't want to get there and be disappointed or something." So, I wasn't trying to expect a lot, but I was... [anticipating] a lot of ways to get involved and stuff because everyone was telling me about that and the things I could when I got here... I looked into the website so everything was like making me wanting to come more... I looked into [the institution and city] because, really, I like to think ahead. I like to plan my future. So, I was already like looking into the city to see if there was a lot of things to do and stuff.

These examples demonstrate the importance of considering pre-sojourn factors in the transition and adjustment experiences of international students of Color. These factors include items such as cultural empathy and openmindedness, emotional stability, motivation for studying abroad, social initiative, flexibility, host language ability, and knowledge about the host country. Many of the participants discussed their motivations for studying in the U.S., including a desire for meeting and interacting with individuals outside of their culture, reflecting previous literature that highlighted the importance of developing interpersonal relationships (Glass \& Gesing, 2018; Soria \& Troisi, 2014; Yao, 2016a). Furthermore, expectations of the host country's culture and politics were major contributing factors.

\section{"When I Got Here...": Helpful Individuals and Challenges with Academic Transitions}

After students' arrival, adjustment was influenced by in-sojourn factors. In order to capture these, we asked participants, approximately one-month into their first semester, what was helpful to them during their initial transition. The purpose was to identify a service or institutional role that students found helpful. Overwhelmingly, students identified people that were helpful to them. Specifically, students cited assigned advisors/coordinators and peers. For example, Jan Are described the helpfulness of his advisor to the transition process. "My advisors have been very helpful. And any question that I do have, I just direct them towards them and they always have an answer for me." Johny also credited his advisor as assisting with his transition. "I can say that my advisors and embassy helped us to transition to the college life." $\mathrm{XL}$ discussed how his transition process was assisted by the staff connected 
to his scholarship program. "We are on scholarship so there are people who are behind it so they help us to be, to transition...They tried to show different [residence] halls, tried to explain where we can get help from...things like that."

In terms of peers assisting with the transition process within the first month, most participants discussed friendships as key contributors to their transition. P described how friends in his scholarship program helped his transition by assisting with his studies. "Like he helps motivating me. He don't want me to lose my scholarship. He wants me to have good marks. He's a good friend and he's so helpful." Esther described the helpfulness of meeting nice people at church to ease her concerns during her transition. "Before I came to the United States, I have like a myth that United States people are bad, some of them...I found some Christian community here... When I come here, I found some people are nice."

NM and Pinky discussed the role of friends from their home country/ culture in their transition, which reflected findings from George Mwangi's (2016) study. NM reflected that "a major part was friends...I met all of the [students from my cultural background]...so I don't feel a lot of transition because, you know, as soon as I came here, I was there. I was having [food from home]." Pinky, likewise, attributed his ease of transition to his "friends and brothers from my home country here...they have helped me to explore the environment." Other peers that contributed to participants' transition were RAs. Johny specifically pointed out that "the RAs who are in the dormitories, they help us a lot when we have a problem...he or she directs you to the right person who can just deal with your problem." Overall, campus involvement and university networks contributed to participants' transition and connections with others from various cultures, as found in previous studies (Glass \& Gesing, 2018; Soria \& Troisi, 2014).

Participants shared that specific individuals and programs that were useful to their transition process were faculty, school services, and international student orientation week. Maria described how "it has been so helpful [to my transition] to go to my teachers' office hours, to talk with them." In terms of school services, participants mentioned the library, student associations, and the offices of Student Involvement and First-Year Experience as helpful to their initial transition. For example, Abi described how a student 
association was very helpful because "when we first came to here, we didn't know where to go and where to live, and they provided us space to live. Before that, before the halls open...That was very helpful to transition from my country to here."

As previously mentioned, international student orientation was highlighted as a key factor in easing participants' initial transition. Lenny described how orientation week "helped me to know where my classes are, meet some new people." John Doe held similar sentiments of meeting new people. "When I got here, I got...to meet other people, other students. I got to really experience what college life is like." However, Ricky discussed how orientation aided his overall transition. "The very first we came, we had international students orientation. It tried to cover most of all the things we'll be needing from day to day...[it] played a big role in getting me adjust into the system easily." Thus, co-curricular and curricular programs, such as orientation and first-year experience classes, have been found to better prepare international students for their transition to college (Brunsting, Smith, \& Zachry, 2018; Yan \& Sendall, 2016)

Participants were additionally asked what was difficult for them in their initial transition, to which responses varied. Some responses focused on academic experiences, comparing teaching and learning styles from their home country to their adjustment in the new academic environment. Hun described difficulties with studying and needing to "change our like study habit...you need more extra work [here]...Have to study like more, like more detail or extra work." Esther stated that "here everything is internet-based, which is different from our country."

Lenny described challenges with language in terms of teaching and learning, which was a common issue in previous studies that examined language and socio-cultural adjustment (Briguglio \& Smith, 2012; Edwards et al., 2007; Li et al., 2010; Yao, 2016a, 2016b). "In our country, we would study in English and then mix it up with our mother tongue and the teachers to not really know English very well, and I thought like it's gonna be difficult for me since English is not my language." He further expanded on the differences by describing that "in our country most of learning is theoretical; you just go and read your books. Here it's practical. Of course you have to read but again in the class you do some practices." 
Among the additional difficulties and needs referenced for a successful transition was the topic of time management. For example, Ricky talked about concerns managing time and juggling responsibilities.

You think of college as the place you're not going to be having a lot of duties to work on. So at the very first moment, we're here, we had a lot of tasks to do. Mostly you have to plan them for yourself. Know the assignments, due dates. Know the different interaction with other people you have to also put into consideration. You have to think of your own time, also...[It came] as a surprise to me. Such as planning for time, I thought it wouldn't be hard.

Jan Are discussed correctly expecting life to be busy. "I expected it to be pretty hectic, a lot of assignments cuz I've heard a lot about college life. So yeah, I expected it to be very busy. Yeah, which is something that I was right about." Furthermore, Pinky mentioned learning that he "must manage my time and I'm trying to manage the time. Like time management is one of the responsible factors for the student."

These examples from the study participants demonstrate how in-sojourn factors, such as social support and social contact with both host nationals and other international students, can influence their transition and adjustment experiences. Social supports through assigned advisors/coordinators, peers, programs, and university systems were all identified as key contributions to participants' initial transition process. Furthermore, in-sojourn factors may have implications in adjustment psychologically and academically, and should be considered when creating support structures.

\section{"In My First-Year...": Reflections on the Transition to College}

Reflecting upon their first full year studying in the U.S., participants were asked about their transition overall, as well as what they wish they would have done differently in their first year. The purpose of these questions was to help researchers understand in-sojourn factors related to participants' transition experiences over time and in hindsight. Some participants identified their academic advisors, intercultural aids, and residential advisors as being helpful to them during their first year. Johny stated,

My intercultural aid... she's the one I knew before I came here. She help me before I came here because we chatted on Facebook...Sometimes I 
stop by her office...not only because I have a major issue to talk with her, but just because I would like to say hi.

This example supports Mesidor and Sly's (2016) recommendation and argument that having an assigned mentor, or in this case, an intercultural aid, for incoming students helps to facilitate the adjustment process.

Faculty were also identified as helpful to the participants' transition over their first full year. Maria mentioned how her transition was assisted by "go[ing] to my teachers' office hours to talk with them. Like 'Hey, how can I improve? What can I do?' and stuff with that." Benita discussed how faculty "are like really willing to help you...because they care" in comparison to faculty in her home country. NM described how the teaching styles of his professors were helpful to his studying and adjustment to learning styles different from his home country. "I think, I love the teaching style here. They are taking on the very first part that everybody can understand, everybody can grasp. So I love that."

Looking back at their transition experiences during their first year studying in the U.S., many participants discussed that they wish they would have gotten more involved in activities and that they would have engaged with their professors more often. Ricky stated,

I should have spent more time outside the room in the first month, because in the first month you go to class, you come from class, you just go to your room...You don't go out to connect with some other people... So, it's more like you're just staying in your comfort zone, yeah. But as time goes on, I just tried something new every day until you feel like you're really comfortable with being out.

Esther had similar sentiments about getting out of her comfort zone. "In my first year...not getting out of my comfort zone, yeah...be involved with those opportunities which are offered to freshmen students. They were really nice opportunity that I missed not because of them, but because of me." Sam talked about how he "probably would've tried to branch out more because freshman year I think it's really easy to meet as many people as possible...it's just easy to just going out and talking to someone. You can easily make a new friend."

Regarding engagement with professors, Lenny described that he did not engage with his professors much in his first year, but thinks that should change because "professors can act as mentors too, if you let them know your goals and your aspirations, they're able to help you, give you advice." 
Additionally, XL mentioned that his anxiety about courses could have been eased if someone would have been around to tell him "Just don't stress, go and ask your professor."

The in-sojourn factors of social support and social contact with both host nationals and other international students were clearly demonstrated throughout the participants' overall transition and adjustment experiences. The importance of friends and supportive staff, faculty, and institutional services were evidenced by many of the participants. The interactive component of participants' transition to college was evident in how they reflected on the importance of people (i.e., domestic students, instructors) and getting involved on campus, which corroborated findings from multiple studies (Glass \& Gesing, 2018; Soria \& Troisi, 2014). Even the reflection of what they wish they could have done differently in their first year demonstrated their desire for connection and support.

\section{Recommendation for Practice}

Our participant narratives indicated that international students of Color rely on many pre-sojourn and in-sojourn factors to assist with their transition and adjustment process. The overall findings of this study demonstrate that participants had to navigate multiple issues throughout their transition, including expectations, expectation gaps, social supports/structures or lack thereof, host country culture and political climate, and peers/friends. One factor that repeatedly arose in both the pre-arrival and post-arrival experiences was that of social support. Whether participants discussed certain individuals that contributed to their successful transition and adjustment, or the desire to connect and engage, social support was crucial to their transition experience.

Student affairs practitioners should be intentional in facilitating peer, staff, and faculty connections for international students of Color, ensuring they have the opportunity to develop networks of support to aid in their transition to college, both early in the first year and beyond. For example, many campuses can expand their social programming for international students by inviting other key partners to help connect with and support international students of Color. Staff and students from multicultural and/or identity-based campus centers can provide guidance on navigating political 
issues and climate in the U.S. for international students of Color, which could be particularly important for those who may face different racial dynamics than what they experienced in their home countries. These campus partners would also be able to offer expertise on how to report any discriminatory experiences students may face while on campus. Feedback from the participants in this study supports the need for this greater facilitation of campus support and connection to transition resources. Collaborative efforts to support this student population are essential because international student support falls under the purview of all student affairs functional areas (Yao \& George Mwangi, 2017).

We also recommend for the inclusion of international students as part of the development of programs that support their transition, which is especially important for international students of Color who have multiple identities (e.g., nationality, ethnicity, religion). Major (2005) recommends including international peers in the planning of orientation and transition programming. Having recently experienced the transition process themselves, needs such as pre-arrival communication or general transportation challenges could be addressed because it is likely that those who have gone through the process have already experienced the challenges. For example, orientation programs can utilize international student mentors to incoming international students of Color to provide peer support and an early connection to campus. Mentors can use technology like social media to connect with incoming students before their arrival in the U.S., and then guide them through the orientation process in small groups to both aid in transition but also provide an important peer connection.

Additionally, our participants indicated difficulty in transitioning academically to college. We suggest earlier contacts with international students through videos and group chats that can be accessed via email, web, or social media prior to students' arrival to campus. Online videos and orientation workshops about preparing for academic study in the U.S., such as time management, engaging with faculty, and learning as a non-native English speaker, would provide international students of Color with the information needed to aid in their academic transition to college in a new country. These early contact videos or group chats can be facilitated by teams of faculty, student affairs administrators, and peer mentors as a way to provide comprehensive and varied perspectives on the transition to college. 


\section{Limitations and Recommendations for Future Directions}

There are several limitations of this study and implications for future research. First, over half of our participant sample came from the same region. This may include findings that represent the specific transition and adjustment experiences of African international students. Despite the potential limitation of a large representative sample from one region, we also view this representation as an opportunity to obtain deeper insights and knowledge about international students of Color from Central Africa.

Another potential limitation of this study was the changes to our sample size based on the longitudinal nature of this study. In our first interview, we had 19 participants. In our second interviews our participant sample decreased to 15 students, and in our final interview, only 12 participants returned. While the research team corresponded with participants via email encouraging them to return, some students were non-responsive leading to our decrease in sample size throughout our three interviews. Despite this limitation, the decreasing number of participants was expected as a result of a longitudinal study, and despite the drop in numbers, we were able to continue to gather rich data from returning participants.

We recommend several directions for future research as a way to mitigate some of our limitations. We suggest delving deeper into the nuances of specific populations of international students of Color. For example, narrowing the focus of the project specifically to international students who identify as African men may provide deeper insights into their expectations and transition experiences to the current racial dynamics of the United States. As previously mentioned, the ways in which international students of Color (e.g., Black international students, Chinese international students) experience college can differ among international student populations. Thus, targeted research on specific international student populations may illuminate how they navigate the current geo-political dynamics affecting higher education. We also suggest researching how institutions prioritize the transition programs and topics for international students of Color, specifically by conducting studies that explore pre-arrival orientations and preparation for international students of Color. A specific focus should be on the pre-arrival processes that international offices, student life, and new student orientation 
offer to assist international students of Color in college. Implications for institutional priorities would assist in re-envisioning and re-imagining innovative ways for how orientation and transition programs are crafted for international students of Color arriving at U.S. college campuses.

Finally, our findings heavily describe and dissect the experiences and perceptions of international students of Color during the adjustment phase. While this is extremely important, additional studies could focus on all aspects of Schartner and Young's (2016) model, including insights on the adaptation processes. Particularly, additional studies could examine the unique distinction between the adjustment and adaptation experiences of international students of Color. Further, longitudinal studies could also explore the adaptation stages of international students of Color. This could include studies that follow international students of Color transition, adjustment, and adaptation outside of their first year of college.

Through the personal reflections of our participants, transition and adjustment experiences are shown to be unique to each individual; but as also indicated by the findings, these experiences have common threads and factors. Thus, these findings demonstrate that transition and adjustment experiences over time are indeed comprised of the three intertwined areas - academic, psychological, and sociocultural, as discussed by Schartner and Young (2016). There is need to understand and dissect the transition experience for international students of Color, specifically, in order to provide the appropriate support and services to this population during the process. 


\section{References}

Abe, J., Talbot, D. M., \& Gellhoed, R. (1998). Effects of a peer program on international student adjustment. Journal of College Student Development, 39, 539-547.

Andrade, M. S. (2006). International students in English-speaking universities: Adjustment factors. Journal of Research in International Education, 5(2), 131-154.

Briguglio, C., \& Smith, R. (2012). Perceptions of Chinese students in an Australian university: Are we meeting their needs?. Asia Pacific Journal of Education, 32(1), 17-33.

Brunsting, N. C., Smith, A. C., \& Zachry, C. (2018). An academic and cultural transition course for international students: Efficacy and socioemotional outcomes. Journal of International Students, 8(4), 14971521.

Brunsting, N. C., Zachry, C., \& Takeuchi, R. (2018). Predictors of undergraduate international student psychosocial adjustment to US universities: A systematic review from 2009-2018. International Journal of Intercultural Relations, 66, 22-33.

Creswell, J., \& Poth, C. (2018). Qualitative inquiry and research design: Choosing among five approaches (4th ed.). Thousand Oaks, CA: SAGE Publications, Inc.

Denzin, N. K., \& Lincoln, Y. S. (2013). Collecting and interpreting qualitative materials (4th ed.). Thousand Oaks, CA: SAGE Publications, Inc.

Edwards, V., Ran, A., \& Li, D. (2007). Uneven playing field or falling standards?: Chinese students' competence in English. Race Ethnicity and Education, 10(4), 387-400.

Fowler, S. M., \& Blohm, J. M. (2004). An analysis of methods for intercultural training. In D. Landis, J. Bennett, \& M. Bennett (Eds.), Handbook of Intercultural Training (3rd ed.) (pp. 37-85). Thousand Oaks, CA: SAGE.

Fries-Britt, S., George Mwangi, C. A., \& Peralta, A. M. (2014). Learning race in the U.S. context: Perceptions of race among foreign-born students of color. Journal of Diversity in Higher Education,7(1), 1-13. 
George Mwangi, C. A., \& Fries-Britt, S. (2015). Black within black: The perceptions of black immigrant collegians and their US college experience. About Campus, 20(2), 16-23.

George Mwangi, C. A. (2016). Exploring sense of belonging among black international students at an HBCU. Journal of International Students, 6(4), 1015-1037.

Glass, C. R., \& Gesing, P. (2018). The development of social capital through international students' involvement in campus organizations. Journal of International Students, 8(3), 1274-1292.

Glass, C. R., \& Westmont, C. M. (2014). Comparative effects of belongingness on the academic success and cross-cultural interactions of domestic and international students. International Journal of Intercultural Relations, 38, 106-119.

Hayes, R. L., \& Lin, H. (1994). Coming to America: Developing social support systems for international students. Journal of Multicultural Counseling \& Development, 22(1), 7-16.

Institute of International Education. (2018, November 13). Open doors 2018 : Report on education international exchange. Retrieved from https:// www.iie.org/en/Research-andInsights/Open-Doors/Open-Doors2018-Media-Information

Jindal-Snape, D., \& Ingram, R. (2013). Understanding and supporting triple transitions of international doctoral students: ELT and SuReCom models. Journal of Perspectives in Applied Academic Practice, 1(1), 17-24.

Lee, J., \& Rice, C. (2007). Welcome to America? International student perceptions of discrimination. Higher Education, 53, 381-409.

Li, G., Chen, W., \& Duanmu, J. L. (2010). Determinants of international students' academic performance: A comparison between Chinese and other international students. Journal of Studies in International Education, 14(4), 389-405.

Major, E. M. (2005). Co-national support, cultural therapy, and the adjustment of Asian students to an English-speaking university culture. International Education Journal, 6(1), 84-95. 
Merriam, S., \& Tisdell, E. J. (2016). Qualitative research: A guide to design and implementation (4th ed.). San Francisco, CA: Jossey-Bass.

Mesidor, J. K., \& Sly, K. F. (2016). Factors that contribute to the adjustment of international students. Journal of International Students, 6(1), 262282.

Miles, M., Huberman, M., \& Saldaña, J. (2014). Qualitative data analysis: A methods sourcebook (3rd ed.). Thousand Oaks, CA: SAGE Publications, Inc.

Pitts, M. J. (2009). Identity and the role of expectations, stress, and talk in short-term student sojourner adjustment: An application of the integrative theory of communication and cross-cultural adaptation. International Journal of Intercultural Relations, 33(6), 450-462.

Rienties, B., Beausaert, S., Grohnert, T., Niemantsverdriet, S., \& Kommers, P. (2012). Understanding academic performance of international students: the role of ethnicity, academic and social integration. Higher Education, 63(6), 685-700.

Russell, J., Rosenthal, D., \& Thomson, G. (2010). The international student experience: Three styles of adaptation. Higher Education, 60(2), 235249.

Ryan, J. (2005). Improving teaching and learning practices for international students: Implications for curriculum, pedagogy and assessment. In J. Carroll \& J. Ryan (Eds.), Teaching international students: Improving learning for all (pp. 92-101). Abingdon: Routledge.

Saldaña, J. (2016). The coding manual for qualitative researchers. Thousand Oaks, CA: SAGE Publications, Inc.

Sam, D. L. (2001). Satisfaction with life among international students: An exploratory study. Social Indicators Research, 53(3), 315-337.

Schartner, A., \& Young, T. J. (2016). Towards an integrated conceptual model of international student adjustment and adaptation. European Journal of Higher Education, 6(4), 372-386.

Seidman, I. (2006). Interviewing as qualitative research: A guide for researchers in education and the social sciences (3rd ed.). New York, NY: Teachers College Press. 
Smith, R. A., \& Khawaja, N. G. (2011). A review of the acculturation experiences of international students. International Journal of Intercultural Relations, 35(6), 699-713.

Soria, K. M., \& Troisi, J. (2014). Internationalization at home alternatives to study abroad: Implications for students' development of global, international, and intercultural competencies. Journal of Studies in International Education, 18(3), 261-280.

Stake, R. E. (1995). The art of case study research. Thousand Oaks, CA: SAGE Publications, Inc.

Takahashi, A. (2009). Self-perception of English Ability: Is it related to proficiency and/or class performance? Niigata Studies in Foreign Languages and Cultures, 14, 39-48.

Trice, A. G. (2004). Mixing it up: International graduate students' social interactions with American students. Journal of College Student Development, 45(6), 671-687.

Ward, C., Bochner, S., \& Furnham, A. (2005). The psychology of culture shock. Hove: Routledge.

Yan, Z., \& Sendall, P. (2016). First year experience: How we can better assist first-year international students in higher education. Journal of International Students, 6(1), 35-51

Yao, C. W. (2015). Sense of belonging in international students: Making the case against integration to U.S. institutions of higher education. Comparative and International Higher Education, 7(1), 6-10.

Yao, C. W. (2016a). Unfulfilled expectations: Influence of Chinese international students' roommate relationships on sense of belonging. Journal of International Students, 6(3), 762-778.

Yao, C. W. (2016b). "Better English is the better mind": Influence of language skills on sense of belonging in Chinese international students. Journal of College and University Student Housing, 43(1), 74-88.

Yao, C. W. (2018). "They don't care about you”: Chinese international students' experiences with neo-racism and othering on a U.S. campus. Journal of the First-Year Experience and Students in Transition, 30(1), 87-101. 
Yao, C. W., \& George Mwangi, C. A. (2017). Invited Editorial: Role of Student Affairs in International Student Transition and Success. Journal of International Students, 7(4), i-iii.

Yao, C. W., George Mwangi, C. A., \& Malaney Brown, V. K. (2019). Exploring the intersections of transnationalism and Critical Race Theory. Race, Ethnicity, and Education, 22(1), 38-58.

Yin, R. K. (2018). Case study research and applications: Design and methods (6th ed.). Thousand Oaks, CA: SAGE Publications, Inc. 